\section{Late onset post-LASIK keratectasia with reversal and stabilization after use of latanoprost and corneal collagen cross-linking}

\author{
Aleksandar Stojanovic, ${ }^{1,2}$ Xiangjun Chen, ${ }^{2}$ \\ Linyan Zheng, ${ }^{3}$ Yile $\mathrm{Xu},{ }^{3}$ \\ Filip Stojanovic, ${ }^{2}$ Tor Paaske Utheim ${ }^{2}$ \\ 'Eye Department, University Hospital of \\ North Norway, Tromso, Norway; \\ 2SynsLaser Kirurgi AS, Tromso/Oslo, \\ Norway; ${ }^{3}$ School of Ophthalmology and \\ Optometry and Eye Hospital, Wenzhou \\ Medical College, Wenzhou, Zhejiang, \\ China
}

\section{Abstract}

We report a case of late onset keratectasia after laser in situ keratomileusis (LASIK) and its quick reversal and stabilization after use of latanoprost and riboflavin/ultraviolet-A corneal collagen cross-linking (CXL). A 39-year-old man with normal intraocular pressure developed a rapid deterioration of vision in his left eye 6 years after LASIK-retreatment for high myopic astigmatism. Keratectasia was diagnosed by corneal topography and ultrasound pachymetry. After two months of treatment with latanoprost and a minor intraocular pressure reduction, uncorrected distance visual acuity improved from 20/100 to 20/20 and corneal topography showed reversal of keratectasia. CXL was performed after the reversal to achieve long-term stabilization. At 1, 3, 6, 13 and 39 months followup exams after the CXL, stable vision, refraction, and topography were registered. This case shows that keratectasia may rapidly occur several years after LASIK and that a quick reversal and stabilization may be achieved by use of latanoprost followed by CXL.

\section{Introduction}

Although several risk factors for keratectasia after laser in situ keratomileusis (LASIK) have been identified and screening techniques continue to improve, post-LASIK keratectasia still occurs. ${ }^{1}$ A case of transient post-LASIK keratectasia associated with a marked elevation of intraocular pressure (IOP), where the keratectasia subsided promptly after IOP normalization, has previously been reported. ${ }^{2}$ The current study reports a case of late onset postLASIK-keratectasia associated with normal IOP, where reversal of keratectasia occurred after only minor IOP reduction after use of latanoprost. Collagen cross-linking (CXL) was subsequently used to successfully stabilize the result.

\section{Case Report}

A 39-year-old male truck driver underwent uneventful bilateral LASIK in October 2001. The patient had no previous history of eye rubbing, trauma, atopy, or any eye disease. No family history of keratoconus was reported. His corrected distance visual acuity (CDVA) before LASIK was 20/16 in both eyes. For the right and the left eye the preoperative manifest refraction was $-6.75-3.50 \times 156$ and $-6.75-5.00 \times 4$, keratometry at orthogonal meridians within the central $3 \mathrm{~mm}$ was $44.40 \mathrm{D} / 41.90 \mathrm{D} \times 165^{\circ}$ and 44.60D $/ 41.20 \mathrm{D} \times 7^{\circ}$. Preoperative IOP (measured by Goldmann applanation tonometry, corrected for pachymetry) was $14 \mathrm{mmHg}$ in both eyes. Orbscan II (B\&L, Rochester, NY, USA) corneal topography showed no morphological signs of increased risk for ectasia. The orthogonal asymmetry within the central $3 \mathrm{~mm}$ was 1.3D and 1.4 D and the highest point on posterior floating elevation map was 35 and 37 microns for the right and left eye, respectively. Central corneal thickness measured by ultrasonic pachymetry (Corneo-Gage Plus, Sonogage Inc., Cleveland, OH, USA) was 586 microns and 593 microns, and the planned ablation depth was 128 microns and 135 microns, for the right and the left eye respectively. Emmetropia within the optical zone of $5.5 \mathrm{~mm}$, and transition zone of $6.5 \mathrm{~mm}$ was
Correspondence: Aleksandar Stojanovic, Fløyvn. 32, 9020 Tromsdalen, Norway.

Tel. + 47.9069.3319 - Fax: + 47.7764.7929.

E-mail: aleks@online.no

Key words: keratectasia, LASIK complication, CXL.

Contributions: the authors contributed equally.

Conflicts of interests: the authors have no potential conflicts of interests.

Received for publication: 1 January 2012.

Revision received: 1 January 2012.

Accepted for publication: 14 January 2012.

This work is licensed under a Creative Commons Attribution NonCommercial 3.0 License (CC BYNC 3.0).

CCopyright A. Stojanovic et al., 2012

Licensee PAGEPress, Italy

Eye Reports 2012; 2:e2

doi:10.4081/eye.2012.e2

attempted. The planned flap thickness was 160 microns, leaving the minimal planned residual stroma at 298 microns in both eyes. Hansatome (B\&L, Rochester, NY, USA) microkeratome with a 160-micron head and an 8.5 $\mathrm{mm}$ ring was used on both eyes. Intraoperative flap thickness, as measured by subtraction pachymetry, was 146 and 158 microns in the right and the left eye, respectively. LaserSight, Astrascan (LaserSight, Orlando, FL, USA), 200 $\mathrm{Hz}, 1 \mathrm{~mm}$ flying-spot laser was used for the ablation.
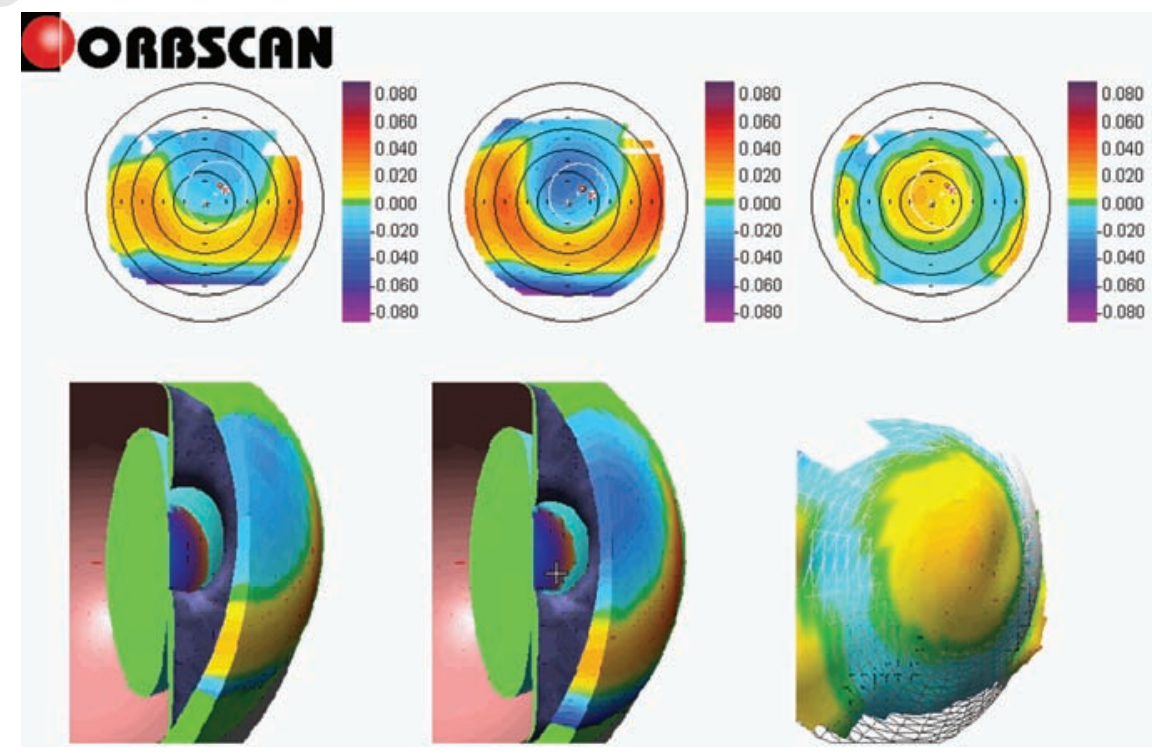

Figure 1. Anterior surface elevation map after the LASIK-retreatment in 2002 (left), after the acute visual deterioration in 2007 (center) and the difference between the two, showing the anterior surface protrusion (right). 

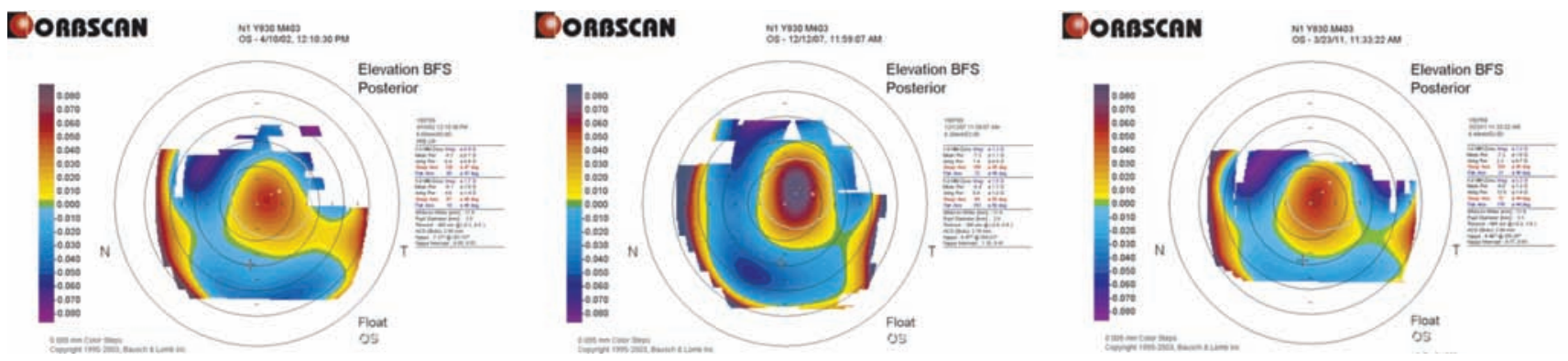

Figure 2. Posterior floating elevation after the LASIK-retreatment in 2002 (left) (45 microns), after the acute visual deterioration in 2007 (center) (85 microns) and after the treatment with latanoprost and collagen cross-linking (right) (55 microns).

\section{DORBSCAN}
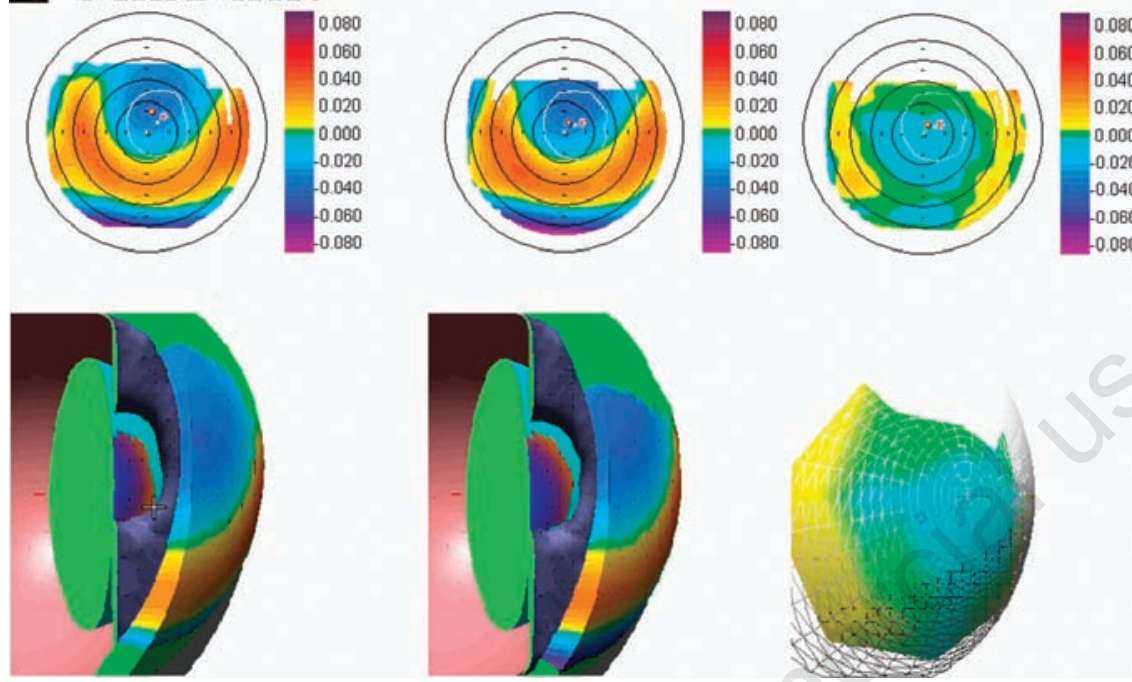

Figure 3. Anterior surface elevation map at the acute visual deterioration (left), after the treatment with latanoprost (center) and the difference between the two, showing the regression of the anterior surface protrusion (right).

After the initial surgery, the patient's uncorrected distance visual acuity (UDVA) was 20/65 in both eyes, with CDVA of 20/20 in both eyes, corrected with $-2.00-1.25 \times 175$ and -1.50 $1.00 \times 170$. The central ultrasound pachymetry was 505 and 502 microns for the right and the left eye, respectively. Retreatment using the flap re-lift technique aiming at emmetropia was performed in January 2002. The ablation depth of the retreatment was 49 and 39 microns and the calculated minimal residual stromal thickness was 296 and 303 microns for the right and the left eye, respectively. After the retreatment, the patient achieved UDVA of 20/20 in both eyes and there were no signs of keratectasia on Orbscan II topography at the follow-up exam 3 months after the surgery. At that point the ultrasound central corneal pachymetry was 463 and 470 microns, and the highest point on the posterior floating elevation map was 43 and 45 microns for the right and left eye, respectively.
The patient reported five years of stable and good vision until November 2007, at which point he experienced an acute and progressive worsening in his left eye, which could not be corrected with spectacle glasses or soft contact lenses. On examination performed on December 12, 2007, UDVA was 20/25 and 20/100, with CDVA 20/20 and 20/60, corrected with $-0.25-0.50 \times 180$ and $-1.00-1.50 \times 145$, for the right and the left eye respectively. Right eye showed unremarkable clinical and topography findings. Orbscan II topography analysis of the left eye revealed signs of keratectasia, showing protrusion on the anterior elevation map (Figure 1), as well as the maximum height on the posterior floating elevation map of 85 microns (Figure 2, center), coinciding with the point of the minimal corneal thickness of 410 microns.

Keratometric map showed an irregular astigmatism with $3.1 \mathrm{D}$ of asymmetry within the central $3 \mathrm{~mm}$. IOP (corrected for pachyme- try) was $14 \mathrm{mmHg}$. Central ultrasound pachymetry was 435 microns. Treatment with latanoprost (Xalatan ${ }^{\circledR}$, Pfizer Inc, New York, NY, USA) once daily was initiated at this time.

According to the patient and the local optometrist, his UDVA improved dramatically within the following two weeks. At the followup examination 2 months after the onset of treatment with latanoprost (February 11, 2008), UDVA and CDVA of the left eye improved to 20/20 and only a minor manifest refractive error remained. Orbscan II anterior surface analysis showed the regression of the protrusion (Figure 3), while the posterior elevation decreased to 55 microns (Figure 2, right). Keratometric map showed a decrease of the irregular astigmatism within the central 3 $\mathrm{mm}$ to $1.5 \mathrm{D}$. The IOP showed a slight decrease to $11 \mathrm{mmHg}$.

On the same day, latanoprost was discontinued and CXL, with $0.1 \%$ riboflavin/dextran solution and $365 \mathrm{~nm}$ ultraviolet-A (UVA) irradiation with UVA-illuminator (UV-X, IROC, Zurich, Switzerland), was performed according to the standard protocol. ${ }^{3}$ The 1-, 3-, 6-, 13- and 39-months follow-up exams after CXL showed consistently stable UDVA of 20/20, stable refraction and no topographic signs of ectasia.

\section{Discussion}

High-grade myopia and astigmatism as well as a history of retreatment are identified risk factors for post LASIK keratectasia. ${ }^{4}$ In the current case keratectasia was topographically diagnosed by moderate protrusion of the anterior surface, marked increase of the height of the posterior elevation and increased asymmetry. The concurrent corneal thinning on ultrasound pachymetry followed the finding.

Guirao and colleagues explained the mechanism of keratectasia as the action of the IOP on the weakened cornea. ${ }^{4,5}$ In our case, in contrast with the previously published case report where the keratectasia reversal occurred with reduction of elevated $\mathrm{IOP}^{2}$ the reversal coincided with only a minor reduction of normal 
IOP after use of latanoprost.

Atmospheric pressure, IOP, and corneal biomechanical strength are factors known to affect the corneal shape and optics. The dynamic balance between these factors seems to be robust in healthy virgin corneas, unaffected by IOP fluctuation in a relatively wide range. ${ }^{2}$ However, one may speculate that a sudden occurrence of keratectasia in the current case, followed by its reversal coinciding with use of latanoprost and a minor decrease of IOP, may imply that the factors keeping the postLASIK cornea stable may not be in a robustly balanced continuum, but rather in a fragile balance.

Hiatt and colleagues ${ }^{6}$ reported a case where IOP reduction was used for reversal of LASIKinduced keratectasia, but the ectasia recurred 3 months after discontinuation of the IOPreducing medication. We chose to treat our patient with CXL rather than continuing the latanoprost, primarily to avoid the need for long-term medication.

Although a certain causality between the use of latanoprost and reversal of post-LASIK keratectasia in the current case cannot be established, and the IOP reduction may not always be effective, it shows that latanoprost may be used in an initial attempt to reverse keratectasia even in normotensive eyes, and that the reversal can be stabilized by use of CXL.

\section{References}

1. Binder PS, Lindstrom RL, Stulting RD, et al. Keratoconus and corneal ectasia after LASIK. J Cataract Refract Surg 2005;31: 2035-8.

2. Toshino A, Uno T, Ohashi Y, et al. Transient keratectasia caused by intraocu- lar pressure elevation after laser in situ keratomileusis. J Cataract Refract Surg 2005;31: 202-4.

3. Wollensak G, Spoerl E, Seiler T. Riboflavin/ultraviolet-a-induced collagen crosslinking for the treatment of keratoconus. Am J Ophthalmol 2003;135:620-7.

4. Guirao A. Theoretical elastic response of the cornea to refractive surgery: risk factors for keratectasia. J Refract Surg 2005; 21:176-85.

5. Comaish IF, Lawless MA. Progressive postLASIK keratectasia; biomechanical instability or chronic disease process? J Cataract Refract Surg 2002;28:2206-13.

6. Hiatt JA, Wachler BS, Grant C. Reversal of laser in situ keratomileusis-induced ectasia with intraocular pressure reduction. $\mathrm{J}$ Cataract Refract Surg 2005;31:1652-5. 